\title{
ANALISIS QUALITY OF SERVICE JARINGAN LOCAL AREA NETWORK MENGGUNAKAN MIKROTIK ROUTERBOARD750 (Studi Kasus: STMIK Royal Kisaran)
}

\author{
Mohd. Siddik \\ Program Studi Sistem Informasi, STMIK Royal Kisaran \\ email: mohdsiddik27@gmail.com
}

\begin{abstract}
The use of computer networks at this time has proven to be a very reliable means of communication and source of information. Government agencies, offices are now using the network as a medium for disseminating information. At present, in the implementation of computer networks, it is very necessary for management to optimize the network itself. Therefore it is necessary to do QoS (Quality of Service) Analysis, in order to get optimal network. QoS (Quality of Service) is a technology that can be applied in computer networks to provide optimal services for network users. With the existence of QoS (Quality of Service) allows network administrators to be able to perform bandwidth management to handle various effects due to congestion (congestion) in packet flow traffic in the network. In performing QoS (Quality of Service), a device that can do bandwidth management to the network is built. Mikrotik Routerboard750 is a network device using Linux-based MicroticOS that can be used in the application of QoS (Quality of Service).
\end{abstract}

Keywords: Computer Network, QoS (Quality of Service), Mikrotik Routerboard750

\begin{abstract}
Abstrak: Penggunaan Jaringan komputer pada saat ini telah terbukti sebagai sarana komunikasi dan sumber informasi yang sangat diandalkan. Seluruh instansi pemerintahan, perkantoran saat ini sudah memanfaatkan jaringan sebagai media sarana penyebaran informasi. Saat ini dalam implementasinya jaringan komputer sangat butuh dilakukan manajemen guna optimalimalisasi jaringan itu sendiri. Maka dari itu perlu dilakukan Analasis QoS (Quality of Service), guna mendapatkan jaringan yang optimal. QoS (Quality of Service) merupakan teknologi yang dapat diterapkan dalam jaringan komputer guna memberikan layanan yang optimal bagi para pengguna jaringan. Dengan adanya QoS (Quality of Service) memungkinkan administrator jaringan untuk dapat melakukan manajemen bandwidth guna menangani berbagai efek akibat terjadinya kemacetan (congestion) pada lalu lintas aliran paket di dalam jaringan. Dalam melakukan $Q o S$ (Quality of Service) dibutauhan sebuah perangkat yang dapat melakukan manajemen bandwidth terhadap jaringan. Mikrotik Routerboard750 adalah perangkat jaringan menggunakana MikrotikOS berbasis Linux yang dapat digunakan dalam penerapan $Q o S$ (Quality of Service) ini.
\end{abstract}

Kata Kunci: Jaringan Komputer, QoS (Quality of Service), Mikrotik Routerboard750 
DOI: https://doi.org/10.33330/jurteksi.v5i2.354

Available online at http://jurnal.stmikroyal.ac.id/index.php/jurteksi

\section{PENDAHULUAN}

Saat ini penggunaan Jaringan komputer bukan lagi merupakan hal yang baru. Setiap perusahaan baik pemerintah maupun swasta, pendidikan dan non pendidikan, telah memiliki jaringan komputer. Penggunaan jaringan komputer menjadi sangat meningkat dikarenakan kebutuhan akan informasi yang menjadi semakin tinggi di era ini. Masalah yang sering terjadi pada jaringan komputer Kampus STMIK Royal Kisaran adalah banyaknya jumlah pengguna yang terhubung menggunakan jalur jaringan komputer yang sama.

Akibatnya adalah jika tidak dilakukan pengaturan maka para pengguna jaringan komputer kampus STMIK Royal Kisaran akan terjadi kemacetan sehingga dapat mengakibatkan semua pengguna yang menggunakan jalur jaringan komputer yang sama tidak dapat melakukan akses terhadap jaringan tersebut.

Melakukan Manajemen bandwith terhadap jaringan komputer Kampus STMIK Royal Kisaran meruapakan hal yang penting. Manajemen bandwith berfungsi untuk mengatur besarnya bandwidth jaringan sehingga setiap pengguna jaringan memperoleh bandwidth dengan alokasi besar banwidth yang sama, sesuai dengan kebutuhan pengguna yang terhubung pada jaringan. Pengguna jaringan Kampus STMIK Royal Kisaran terdiri dari Dosen yang tergabung dengan Struktural, Staf, dan Mahasiswa.

Maka dari itu perlu dilakukan Analasis QoS (Quality of Service), guna mendapatkan jaringan yang optimal dan memuaskan. QoS (Quality of Service) merupakan teknologi yang dapat diterapkan dalam jaringan komputer guna memberikan layanan yang optimal bagi para pengguna jaringan. Dengan adanya $Q o S$ (Quality of Service) memungkinkan administrator jaringan untuk dapat melakukan manajemen bandwidth, guna menangani berbagai efek akibat terjadinya kemacetan (congestion) pada lalu lintas aliran paket di dalam jaringan.

QoS (Quality of Service) merupakan teknologi yang dapat diterapkan dalam jaringan komputer guna memberikan layanan yang optimal bagi para pengguna jaringan. Dengan adanya QoS (Quality of Service) memungkinkan administrator jaringan untuk dapat melakukan analisa dalam melakukan manajemen bandwidth, guna menangani berbagai efek akibat terjadinya kemacetan (congestion) pada lalu lintas aliran paket di dalam jaringan. [1]

Hal tersebut sejalan yang pada hasil penelitiann menyatakan bahwa QoS Quality of Service digunakan untuk tolak ukur dalam melakukan analisa pengelolaan bandwitdh dibagi secara merata guna kualitas koneksi jaringan lebih yang lebih stabil.[2]

Penelitian yang menjelaskan tenang analisa Quality of Servic Dari hasil penelitian disimpulkan melakukan analisa terhadap kualitas layanan internet terbaik. [3]

Layanan internet yang baik salah satunya adalah dengan melakukan pembagian banwidth yang merata. Bandwidth dalam ilmu komputer adalah suatu penghitungan konsumsi data yang tersedia pada suatu telekomunikasi.

Penelitian penggabungan dua ISP dan manajemen bandwidth, pada hasil penelitian ini mendapatkan hasil koneksi jaringan yang stabil. hal ini sejalan dengan penelitian yang dilakukan. [4]

Dalam melakukan QoS (Quality of Service) dibutuhkan sebuah perangkat yang dapat melakukan manajemen jaringan.

Mikrotik Routerboard750 adalah perangkat jaringan yang dapat digunakan. Mikrotik routerboard 
merupakan sebuah perangkat jaringan komputer yang menggunakan Mikrotik RouterOS yang berbasis Linux dan diperuntukkan bagi network.[5]

Berdasarkan uraian di atas, maka pada penelitian ini bertujuan untuk melakukan manajemen bandwidth menggunakan Mikrotik Routerboard750 dengan menerapkan analisis $Q o S$ (Quality of Service) pada jaringan Lokal Area Network yang terdapat pada kampus STMIK Royal Kisaran.

\section{METODE}

Pada tahapan ini melakukan identifikasi masalah terhadap analisa QoS (Quality of Service) yang dilakaukan pada jaringan Lokal Area Network STMIK Royal Kisaran.Pada Tahapan ini dilakukan pengumpulan terhadap studi literature, serta referensireferensi yang berhubungan analisa $Q o S$ (Quality of Service).

Pada tahap perancangan sistem dilakukan dengan terlebih dahulu menggambarkan topologi jaringan yang ada pada kampus STMIK Royal kisaran. nantinya topologi jaringan ini akan menjadi panduan dalam melakukan analisa dan manajemen pada jaringan.

Pada tahapan ini melakukan pengujian terhadap manajemen jaringan yang telah dilakukan sesuai dengan topologi yang telah dirancang. Pengujian ini dilakukan dengan melihat hasil output bandwidth pada masing-masing unit kerja di STMIK Royal Kisaran. Adapun besar output pengujian yang nantinya menjadi acuan dapat dilihat pada tabel 1 .
Tabel 1. Alokasi Bandwidth berdasarkan Unit di STMIK Royal Kisaran

\begin{tabular}{lcc}
\hline \multicolumn{1}{c}{ User } & $\begin{array}{c}\text { Bandwidth } \\
\text { Upload }\end{array}$ & $\begin{array}{c}\text { Bandwidth } \\
\text { Download }\end{array}$ \\
\hline $\begin{array}{l}\text { Biro } \\
\text { Akademik }\end{array}$ & $10 \mathrm{Mb}$ & $10 \mathrm{Mb}$ \\
\hline $\begin{array}{l}\text { Prodi SI Dan } \\
\text { SK }\end{array}$ & $10 \mathrm{Mb}$ & $10 \mathrm{Mb}$ \\
\hline $\begin{array}{l}\text { Dosen SI } \\
\text { Dan SK }\end{array}$ & $10 \mathrm{Mb}$ & $10 \mathrm{Mb}$ \\
\hline Mahasiswa & $20 \mathrm{Mb}$ & $20 \mathrm{Mb}$ \\
\hline
\end{tabular}

Pada tahapan ini dilakukan analisa terhadap hasil dari perancangan sistem. Analisa ini meliputi melihat besar output badwidth yang ada pada setiap unit kerja STMIK Royal Kisaran sesuai dengan tabel perancangan yang telah dibangun.

Tahapan implementasi sistem dilakukan dengan melakukan manajemen jaringan sesuai dengan rancangan yang telah diusulkan dari hasil pada rancangan sistem yang telah dilakukan.

\section{HASIL DAN PEMBAHASAN}

Berdasarkan kepada analisa usulan yang telah disarankan diatas maka tahap selanjutnya adalah melakukan konfigurasi terhadap Mikrotik Routerboard 750, yang dimulai dari konfigurasi interface sesuai dengan Unit kerja STMIK Royal Kisaran, konfigurasi IP Address, konfigurasi DHCP Server, serta melakukan konfigurasi manajemen bandwidthi pada Simple Queue dengan besar badwidth uload dan download.

\section{Topologi Jaringan Kampus}

Dalam pelaksanaan penelitian ini Jaringan komputer yang dianalisis adalah jaringan Local Area Network kampus yang telah terinstalasi di STMIK Royal Kisaran yang nantinya akan 
dilakukan manajemen pada jaringan tersebut. Manajemen ini meliputi pengaturan pembagian bandwidth sesuai dengan analisa rancangan yang telah dilakukan Adapun bentuk dari topologi jaringan Local Area Network yang telah dibangun pada kampus STMIK Royal Kisaran adalah sebagai berikut:

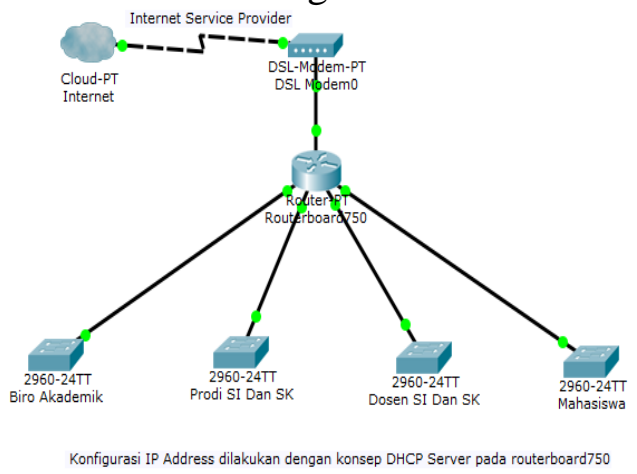

Gambar 1. Topologi Jaringan

\section{Konfigurasi Interface}

Konfigurasi interface pada penelitian ini dilakukan sesuai dengan topologi jaringan Lokal Area Network yang ada dimulai dari hubungan jaringan ke Biro Akademik, Prodi SI dan SK, Dosen SI Dan SK, dan mahasiswa. Adapun hasil dari konfigurasi interface yang dilakukan dapat dilihat pada gambar 2.

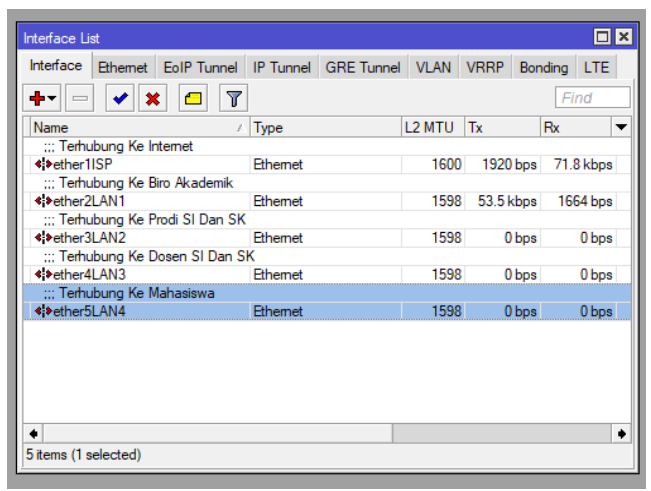

Gambar 2. Konfigurasi Interface

\section{Konfigurasi IP Address}

Adapun Konfigurasi IP Address pada penelitian ini dilakukan dengan menggunakan IP Class $\mathrm{B}$, mengingat IP
Class B memiliki jumlah host yang lebih banyak dari Class $\mathrm{C}$ sehingga pengalaman IP nantinya tidak akan mengalamai masalah kekurangn. Pengalamatan IP Address ini akan dimulai dari hubungan jaringan ke Biro Akademik, Prodi SI dan SK, Dosen SI Dan SK, dan mahasiswa. Adapun hasil dari konfigurasi IP Address yang dilakukan dapat dilihat pada gambar 3 .

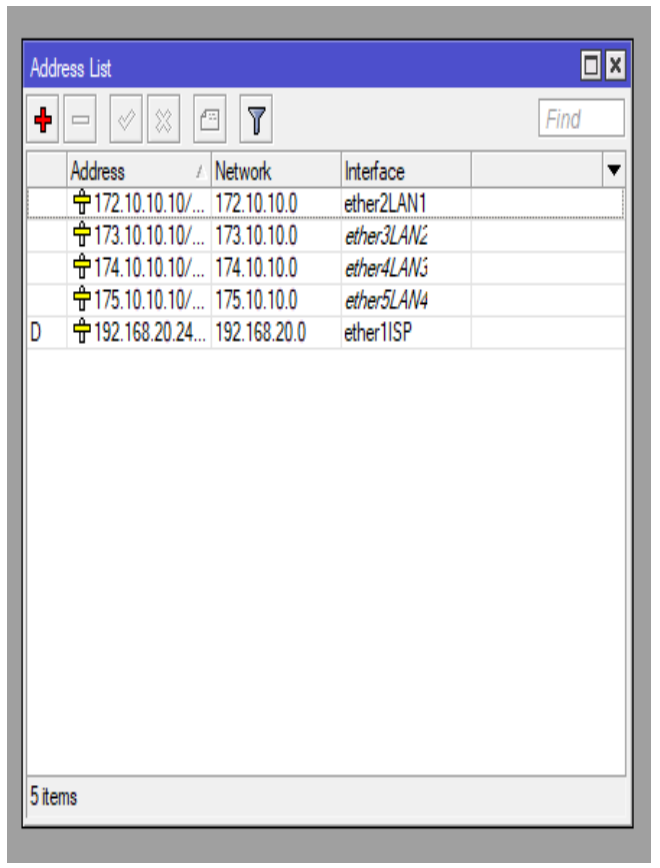

Gambar 3. Konfigurasi IP Address

\section{Konfigurasi DHCP Server}

Adapun Konfigurasi DHCP Server pada penelitian ini dilakukan pada setiap hubungan ke masing-masing unit kerja yang ada pada STMIK Royal Kisaran. yang dimulai hubungan jaringan ke Biro Akademik, Prodi SI dan SK, Dosen SI Dan SK, dan mahasiswa. Adapun hasil dari konfigurasi DHCP Server yang dilakukan dapat dilihat pada gambar 4 . 
DOI: https://doi.org/10.33330/jurteksi.v5i2.354

Available online at http://jurnal.stmikroyal.ac.id/index.php/jurteksi

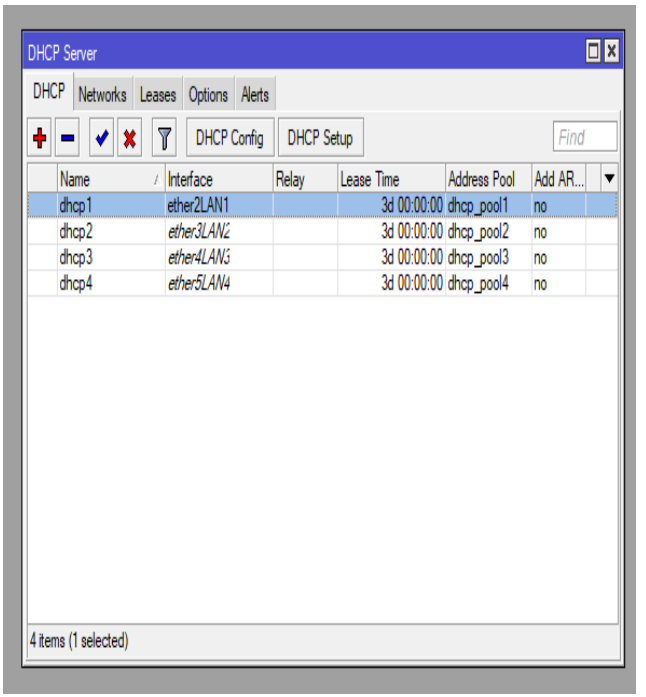

Gambar 4. Konfigurasi DHCP Server

\section{Konfigurasi Manajemen Bandwidth}

Konfigurasi manajemen bandwidth pada penelitian ini dilakukan dengan menggunakan Simple Queues, dimana pembagian bandwidth disesuai dengan rancangan. Manajemen bandwidth dimulai dari hubungan jaringan ke Biro Akademik, Prodi SI dan SK, Dosen SI Dan SK, dan mahasiswa. Adapun hasil dari konfigurasi manajemen bandwidth yang dilakukan dapat dilihat pada gambar 5 .

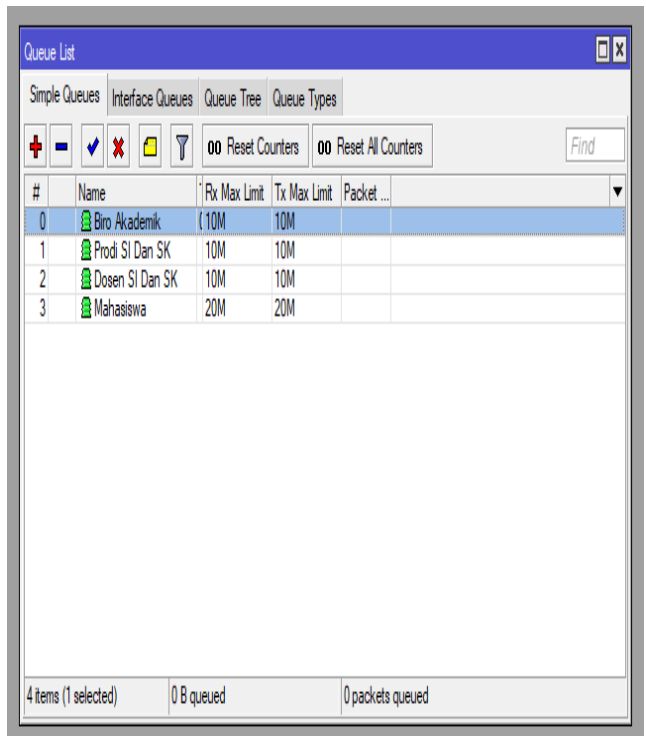

Gambar 5. Konfigurasi Bandwidth

\section{Pengujian Sistem}

Tahapan ini dilakukan untuk melakukan analisa terhadap hasil penelitian yang telah dilakukan. Pengujian ini meliputi pemantauan output bandwidth pada setia unit pada topologi jaringan, yang telah dilakukan manajemen bandwidth. Adapun hasil pengujian ini dapat dilihat pada gambargambar berikut:

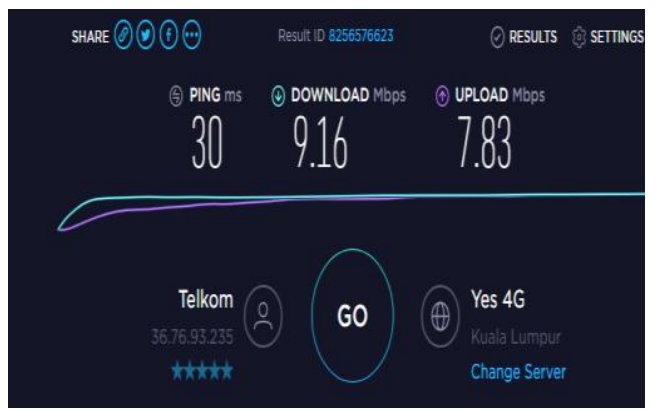

Gambar 6. Hasil Output Bandwidth Ke Biro Akademik

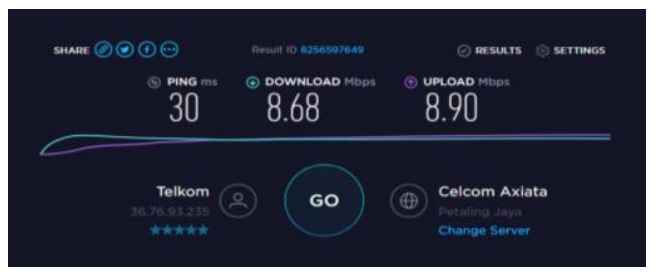

Gambar 7. Hasil Output Bandwidth Ke Prodi SI Dan SK

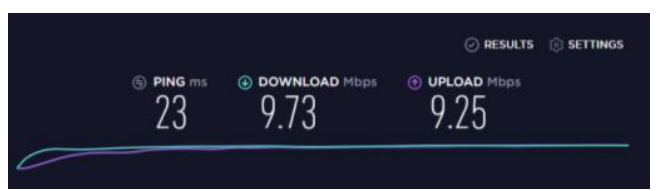

Gambar 8. Hasil Output Bandwidth Ke Dosen SI Dan SK

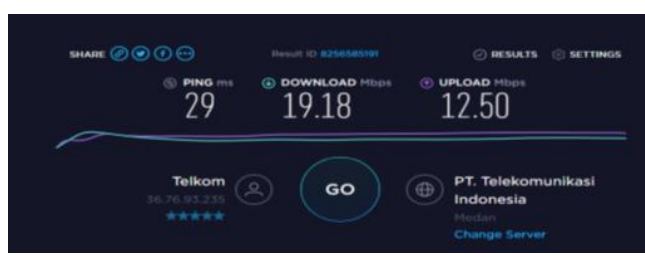

Gambar 9. Hasil Output Bandwidth Ke Mahasiswa 
DOI: https://doi.org/10.33330/jurteksi.v5i2.354

Available online at http://jurnal.stmikroyal.ac.id/index.php/jurteksi

\section{SIMPULAN}

Berdasarkan proses dalam hasil penelitian yang telah dilakukan, maka dapat diambil kesimpulan antara lain:

1. Hasil pengujian manajemen bandwith dengan penerapan QoS menunjukan hasil bandwidth upload dan bandwidth download, tidak melebihi batas maximum kapasitas bandwidth.

2. Sistem dapat bekerja meskipun untuk top maximum bandwidth upload dan bandwidth download tidak mencapai maximum bandwidth upload dan bandwidth download.

\section{DAFTAR PUSTAKA}

[1] Silitonga, P and Iren., 2014. Analisis QoS (Quality of Service) Jaringan Kampus dengan Menggunakan Microtic Routerboard. Jurnal Times, 3(2), pp.19-24.

[2] Riadi, I. and Wicaksono, W.P., 2011. Implementasi Quality of Service Menggunakan Metode Hierarchical Token Bucket. Universitas Ahmad dahlan.

[3] Wulandari, P., Soim, S. and Rose, M., 2017. Monitoring dan Analisis Qos (Quality Of Service) Jaringan Internet pada Gedung Kpa Politeknik Negeri Sriwijaya dengan Metode Drive Test. Prosiding SNATIF, pp.341347.

[4] Siddik, M., Hendro, Y. and Azmi, Z., 2015. Load Balance Dan Pembagian Banwidthpada Jaringan Lan Menggunakanmikrotik Router Board $\mathrm{Rb}$ 750. Jurnal SAINTIKOM Vol, 14(1).
[5] Siddik, Mohd. Implementasi Mikrotik Router Board 750 Sebagai Firewall Blok Situs Pada Jaringan Lan. JURTEKSI ROYAL Vol 3 No 2 (2017). 